\title{
Genetic screening of regulatory regions of pituitary transcription factors in patients with idiopathic pituitary hormone deficiencies
}

\author{
Melitza Elizabeth $^{1} \cdot$ Anita C. S. Hokken-Koelega ${ }^{1,2,3} \cdot$ Joyce Schuilwerve $^{4} \cdot$ Robin P. Peeters $^{4,5} \cdot$ Theo J. Visser $^{4,5}$. \\ Laura C. G. de Graaff ${ }^{3,4,6}$ (D)
}

Published online: 18 December 2017

(c) The Author(s) 2017. This article is an open access publication

\begin{abstract}
Purpose Mutation frequencies of $P R O P 1, P O U 1 F 1$ and $H E S X 1$ in patients with combined pituitary hormone deficiencies (CPHD) vary substantially between populations. They are low in sporadic CPHD patients in Western Europe. However, most clinicians still routinely send DNA of their CPHD patients for genetic screening of these pituitary transcription factors. Before we can recommend against screening of PROP1, POUIF1 and HESXI as part of routine work-up for WesternEuropean sporadic CPHD patients, it is crucial to rule out possible defects in regulatory regions of these genes, which could also disturb the complex process of pituitary organogenesis.

Methods The regulatory regions of PROP1, POUIF1 and HESXI are not covered by Whole Exome Sequencing as they are largely located outside the coding regions. Therefore, we manually sequenced the regulatory regions, previously defined in the literature, of PROP1, POUIF1 and HESXI among 88 Dutch patients with CPHD. We studied promoter SNPs in relation to phenotypic data.

Results We found six known SNPs in the PROP1 promoter. In the POUIF1 promoter, we found one new variant and two known SNPs. We did not find any variant in the HESXI promoter.

Conclusion Although the new POU1F1 variant might explain the phenotype of one patient, the general conclusion of this study is that variants in regulatory regions of PROP1, POUIF1 and HESXI are rare in patients with sporadic CPHD in the Netherlands. We recommend that genetic screening of these pituitary transcription factors should no longer be part of routine work-up for Western-European, and especially Dutch, sporadic CPHD patients.
\end{abstract}

Keywords Transcription factor $\cdot$ Regulatory region $\cdot$ Pituitary $\cdot$ Genetic screening $\cdot$ Growth $\cdot$ Hypopituitarism

Electronic supplementary material The online version of this article (https://doi.org/10.1007/s11102-017-0850-6) contains supplementary material, which is available to authorized users.

Laura C. G. de Graaff

1.degraaff@erasmusmc.nl

1 Dutch Growth Research Foundation, Rotterdam, The Netherlands

2 Pediatrics, Subdivision Endocrinology, Erasmus MC Rotterdam, Rotterdam, The Netherlands

3 Academic Center for Growth Disorders, Erasmus MC Rotterdam, Rotterdam, The Netherlands

4 Internal Medicine, Subdivision Endocrinology, Erasmus MC Rotterdam, Rotterdam, The Netherlands

5 Academic Center for Thyroid Diseases, Erasmus MC Rotterdam, Rotterdam, The Netherlands

6 Department of Internal Medicine, Erasmus MC, University Medical Center, Room D-411, 's Gravendijkwal 230, 3015 CE Rotterdam, The Netherlands

$\begin{array}{ll}\text { Abbreviations } \\ \text { ACTH } & \text { Adrenocorticotropic hormone } \\ \text { CEA } & \text { Conserved element A } \\ \text { CEB } & \text { Conserved element B } \\ \text { CPHD } & \text { Combined pituitary hormone deficiency } \\ \text { DRR } & \text { Distal regulating region } \\ \text { FSH } & \text { Follicle stimulating hormone } \\ \text { GH } & \text { Growth hormone } \\ \text { GHD } & \text { Growth hormone deficiency } \\ \text { GHRH } & \text { Growth hormone releasing hormone (GHRF) } \\ \text { HESX1 } & \text { Homeobox expressed in ES cells 1 } \\ \text { (p)IGHD } & \text { (partial) Isolated growth hormone deficiency } \\ \text { LH } & \text { Luteinising hormone } \\ \text { PCR } & \text { Polymerase chain reaction } \\ \text { POU1F1 } & \text { POU domain, class 1, transcription factor 1 } \\ & \text { (PIT1) } \\ \text { PRL } & \text { Prolactin } \\ \text { PROP1 } & \text { Prophet of POU1F1 }\end{array}$


SNP Single nucleotide polymorphism

SOD Septo-optic dysplasia

T3/T4 Thyroid hormone

TRH Thyrotropin-releasing hormone

TSH Thyroid stimulating hormone

\section{Introduction}

Pituitary hormones are crucial for correct human growth and development. The anterior part of the pituitary ('master gland') is the central regulator of peripheral hormones. It contains somatotrope, lactotrope, gonadotrope, thyrotrope and corticotrope cells producing GH, PRL, LH/FSH, TSH and ACTH, respectively. Pituitary embryogenesis is a complex process, which is orchestrated by a number of signaling molecules and transcription factors [1].

During pituitary organogenesis, regulation of the expression of pituitary transcription factors is crucial for normal pituitary development. Transcription factors bind to short DNA sequences usually located in the promoter region of a gene, to guide and activate DNA transcription. Hesx 1 is one of the earliest transcription factors that appear in the pituitary gland. As studied in mice, Hesxl and Propl exhibit temporally distinct but overlapping patterns of expression over the entire period of pituitary development. They heterodimerize on the same sequence element and Hesx1 suppresses Prop1 expression (and vice versa). Prop1 has to be present before Pou1f1 (formerly called Pit1) can be activated. Therefore the gene was referred to as Prophet of Pit1. However, premature expression of Propl can entirely block pituitary organogenesis [2].

Previous research has shown that bad timing or abnormal amounts of transcription factors can disturb this complex collaboration between transcription factors and lead to abnormal pituitary organogenesis and pituitary hormone deficiencies [3-6]. Since defects in the regulatory regions of a gene can alter expression of the gene, variations in regulatory regions of pituitary transcription factors are likely to also cause isolated or combined pituitary hormone deficiencies. This is supported by the work of Godi et al. [7], who found an association between two polymorphisms within and around a regulatory region in the intron 1 of $P R O P 1$ (rs73346254A and rs148607624 delTAG), and combined pituitary hormone deficiencies (CPHD). Co-presence of the alternative alleles of both SNPs was associated with reduced transcriptional activity as shown by a decreased luciferase activity. An EMSA with oligonucleotide probes carrying the two alternative alleles demonstrated a strong difference in binding specificity of the two allelic sequences for a component present in nuclear extracts from GH4C cells.

Although our knowledge of pituitary organogenesis and its genetics has increased tremendously in the past two decades, the exact genetic background of CPHD has not yet been clarified. Mutation frequencies reported in the literature vary substantially between populations. Figure 1a, b show the wide range of reported mutation frequencies from various countries, the highest prevalences being present in Eastern Europe.

Therefore, the Dutch national HYPOPIT study was initiated, with the aim to determine the prevalence of genetic defects in the Dutch national cohort of patients with idiopathic pituitary hormone deficiencies.

Within the HYPOPIT study, we previously studied Dutch CPHD cases for mutations in PROP1, HESXI, POU1F1, LHX3, LHX4, OTX2, SHH and HHIP [22-24] and patients with Isolated GH Deficiency (IGHD) for GH1, GHRHR, HMGA2 and CDK6 [25-27]. In the cohort of CPHD patients, we found only one mutation, namely a missense mutation in POU1F1. In the IGHD cohort, we found $\mathrm{GH} 1$ mutations in $6 \%$ of the participating families, whereas we did not find any mutations in GHRHR or the regulatory regions of $\mathrm{GH}$.

This illustrates that only a small minority of the Dutch CPHD and IGHD cases can be explained by genetic defects in coding regions of the genes associated with pituitary hormone deficiencies. This is surprising, because the CPHD and IGHD patients in the Dutch cohort have the same phenotype as patients from other countries, where mutations in PROP1, POUIF1 and HESXI are much more prevalent.

Although the chance of finding a mutation in PROP1, POUIF1 and HESXI in a CPHD patient is very low for Western European countries, especially the Netherlands, most clinicians still routinely send DNA of their CPHD patients for genetic screening of PROP1, POU1F1 and HESX1. However, based on the above mentioned findings, we can conclude that defects in PROPI, POUIFI and HESXI are usually not the cause of CPHD in Dutch sporadic CPHD patients. It would therefore make sense to recommend against screening of $P R O P 1, P O U 1 F 1$ and HESXI as part of routine work-up for Dutch sporadic CPHD patients. However, in order to justify such a recommendation, defects in the regulatory regions of these genes should first be ruled out.

The regulatory regions of $P R O P 1, P O U 1 F 1$ and HESX1 are largely located outside the coding regions and are thus not covered by Whole Exome Sequencing. Therefore, in the current study, we manually sequenced regulatory regions of PROP1, POU1F1 and HESXI among 88 patients with CPHD. Since patients with HESXI mutations can initially present with IGHD only, we also screened 92 patients with IGHD. We compared genotype frequencies in our CPHD cohort with those found in healthy controls from the 1000 genomes database and we studied promoter SNPs in relation to phenotypic data. 
Fig. 1 Prevalence of $P R O P 1$, $P O U 1 F 1$ and HESX1 mutations in CPHD patients as reported in the literature, according to country of origin (see "Methods" section for literature search criteria). Apart from the Moroccan data, most populations included both familial and sporadic CPHD cases. For original data, see Ref [8-20]. $?=$ no mutation rate available.

*The exact mutation frequency in French and German sporadic CPHD patients could not be deduced from the literature [13, 21]

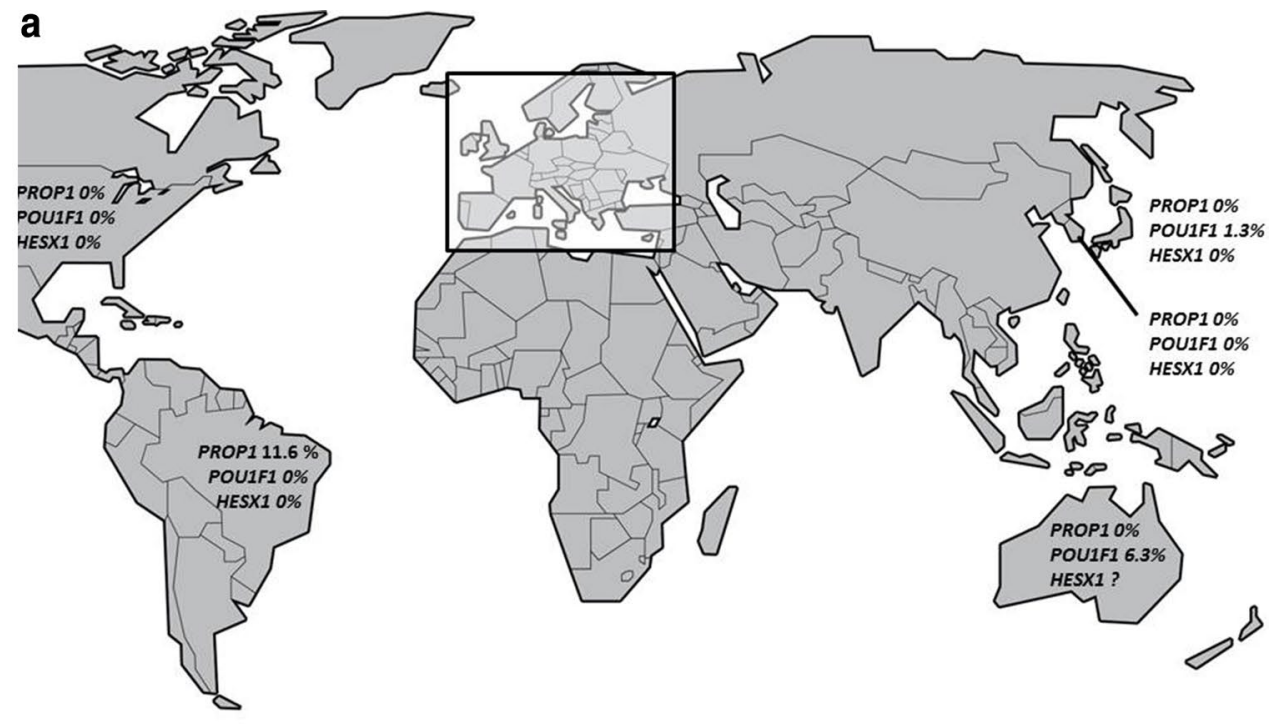

b

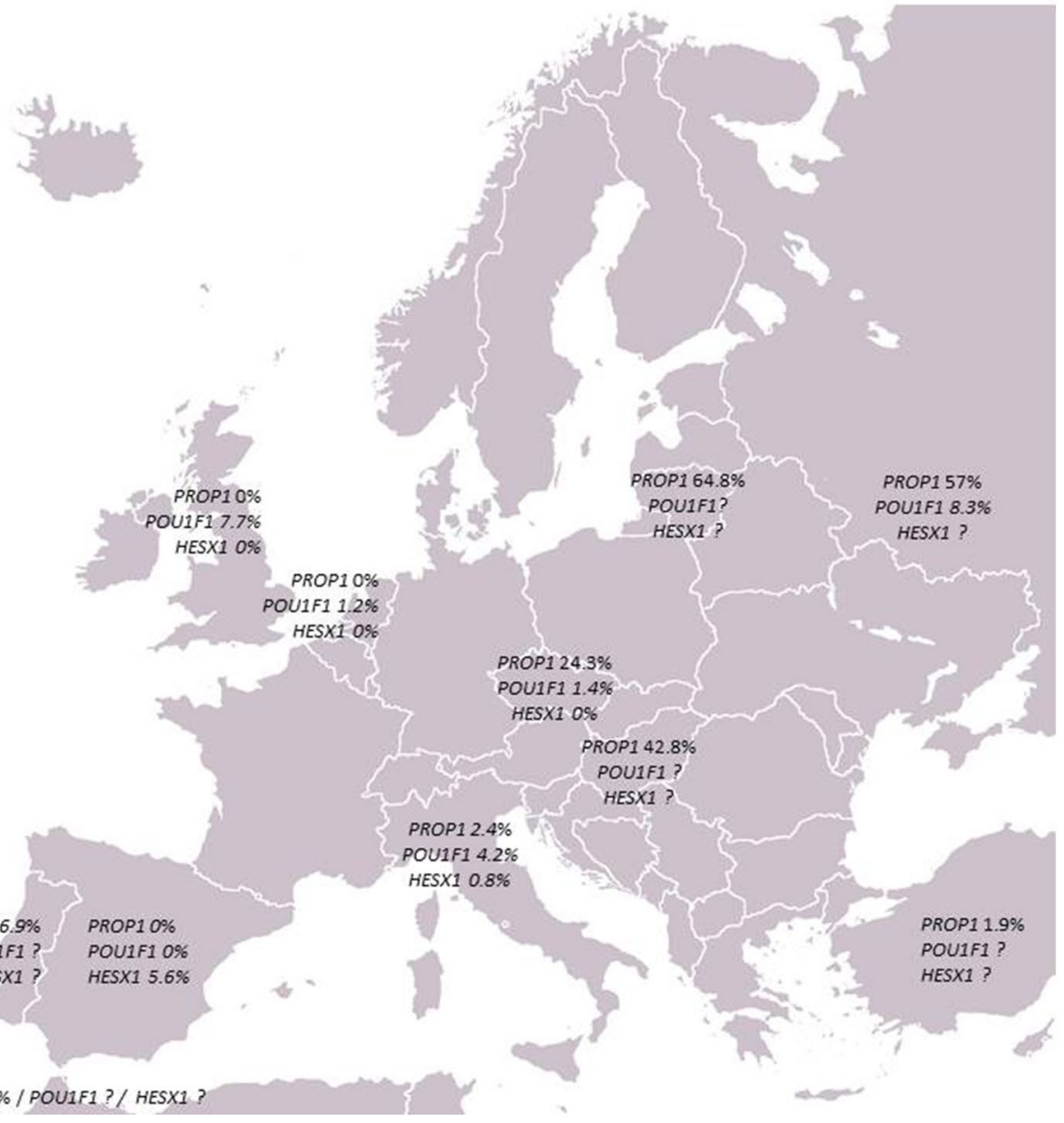

\section{Patients and methods}

\section{Patients}

Clinical data of the patients were collected from the Dutch National Registry of Growth Hormone Treatment, where clinical and laboratory parameters of GH-treated Dutch patients are being registered. We included all GH-treated children and adults registered in the Dutch National Registry of Growth Hormone Treatment between 1992 and 2003, who had deficiencies of $\mathrm{GH}$ and one or more additional hormonal axes and were treated in the hospitals participating in the 
study. Patients with Growth Hormone deficiency (GHD) of known cause, such as a brain tumour, brain surgery, brain irradiation and known syndromes, were excluded. GHD was defined as a peak GH response below $6.7 \mu \mathrm{g} / \mathrm{L}(20 \mathrm{mU} / \mathrm{L})$ to arginine or clonidine test, or $10 \mu \mathrm{g} / \mathrm{L}(<30 \mathrm{mU} / \mathrm{L}) \mathrm{com}$ bined with serum IGF-I $<-2$ SDS. Patients were classified as having severe IGHD or partial IGHD (pIGHD) based on a scoring system including height SDS (HSDS), maximum stimulated GH levels, IGF-I SDS and IGFBP-3 SDS. Central hypothyroidism was defined as abnormal TRH test or TSH levels that were low or inadequate for low (F) T4, using reference ranges of each participating hospital. Central hypocortisolism was defined as abnormal CRF/ACTH/glucagon test or ACTH levels which were low or inadequate for low cortisol. Central hypogonadism was diagnosed when LH, FSH and estrogen/testosterone or LHRH test were low for age, or when spontaneous puberty had not occurred at age 14 years. Prolactin deficiency was defined as abnormal random prolactin or during TRH testing. For all hormone values, reference values of the participating hospitals are available upon request.

The Medical Ethics Committees of all participating hospitals approved the study. Informed consent was obtained from all participating patients and their parents, if patients were younger than 18 years.

\section{Methods}

PCR Genomic DNA was extracted from samples of peripheral venous blood according to standard procedures. For PCR, we used the following Qiagen reagents: 10× PCR buffer, $0.2 \mathrm{mM}$ dNTP mixture and 5 units $/ \mu \mathrm{L}$ Taq DNA Polymerase. After gel electrophoresis, we purified the PCR products using the High Pure PCR product Purification kit
(QIAGEN ${ }^{\circledR}$, Hilgen, Germany) or the Illustra GFX 96 PCR Purification Kit (GE Healthcare ${ }^{\circledR}$, Leiderdorp, the Netherlands) according to the supplied protocols. PCR conditions and amplification programs are available upon request. We studied the regulatory regions of $P O U 1 F 1$ as described by Delhase et al. [28] and the promoter of HESXI as described by Eroshkin et al. [29]. Primer sequences were designed using the Primer3 program. Nucleotide sequences were obtained from Ensembl (PROP1: ENSG00000175325; POUIF1 ENSG00000064835; HESX1 ENSG00000163666). Primer sequences for CEA and CEB of PROPl were kindly provided by Godi et al. [7] and Ward et al. [30]. An overview of the regulatory regions of $P R O P 1, P O U 1 F 1$ and $H E S X 1$ is shown in Fig. 2. The primers were ordered from Integrated DNA Technologies Inc (Iowa, United States), dissolved in sterile $\mathrm{H}_{2} \mathrm{O}$ to a concentration of $50 \mathrm{pmol} / \mu \mathrm{L}$ and stored at $-20{ }^{\circ} \mathrm{C}$ until further use. From this stock, aliquots with a working concentration of $25 \mathrm{pmol} / \mu \mathrm{L}$ were made and stored at $-20^{\circ} \mathrm{C}$.

Sequencing Sequencing was outsourced to Baseclear, a commercial DNA sequencing company in Leiden, the Netherlands, and carried out using an ABI3730XL sequencer. The results were analyzed for mutations using Sequencher4.1 (Genecodes, Michigan, United States).

Statistics We analysed clinical and genotypic data by means of ANOVA and Chi square tests using SPSS version 22.0.

Literature In order to make an overview of $P R O P 1$ mutation frequencies according to country of origin, we performed a pubmed search using ' $P R O P 1$ AND mutation AND combined pituitary hormone deficiency' (filter: English). We only selected articles of which the full text manuscript was
Fig. 2 Overview of regulatory regions of $P R O P 1, P O U 1 F 1$ and HESX1. CEA conserved element A, $C E B$ conserved element B
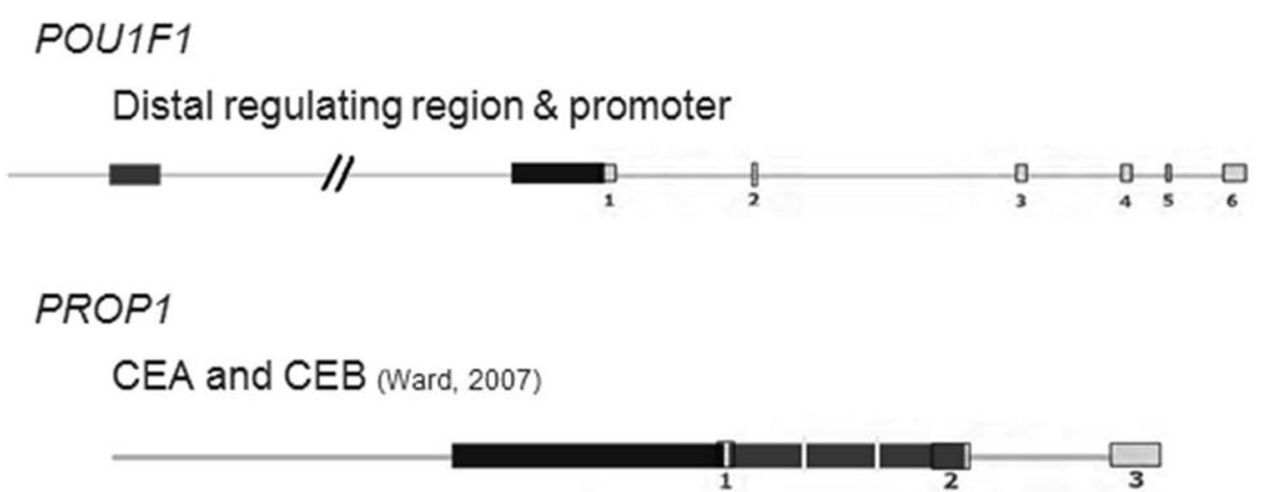

HESX1

Promoter 
available online or sent to us by the authors upon request. Articles in which the country of origin of the patients was mixed or unclear, were excluded.

In silico analysis of new variant We used online software PROMO 3.0 [31] to predict changes in transcription factor binding sites in the $P O U 1 F 1$ promoter region.

\section{Results}

We included 88 CPHD patients $(63 \mathrm{M} / 25 \mathrm{~F})$ and 92 patients (64 M/28 F) with IGHD, either classified as severe ('IGHD') or partial IGHD ('pIGHD'). The male predominance in our cohort is in accordance with the male predominance in the overall Dutch CPHD and IGHD population.

Clinical characteristics of the CPHD and IGHD patients are shown in Table 1. All CPHD patients had at least GHD and thyroid hormone replacement, while $79 \%$ of the patients additionally required glucocorticoid hormone replacement and $85 \%$ required induction of puberty. Hypoprolactinaemia was present in only $15 \%$ of CPHD patients tested and four patients $(5 \%)$ had diabetes insipidus. Neonatal jaundice, neonatal hypoglycaemia and micropenis, suggestive of early

Table 1 Clinical characteristics of the CPHD and (p)IGHD patients in this study

\begin{tabular}{lll}
\hline & CPHD & $(\mathrm{p}) \mathrm{IGHD}$ \\
\hline Sex & $63 \mathrm{M} / 25 \mathrm{~F}$ & $64 \mathrm{M} / 28 \mathrm{~F}$ \\
Birth weight $(\mathrm{kg})$ & $3.0(0.8)$ & $3.1(0.6)$ \\
(SDS) & $-0.6(1.4)$ & $-0.7(1.3)$ \\
Birth length $(\mathrm{kg})$ & $49.4(3.0)$ & $48.1(3.6)$ \\
(SDS) & $-0.3(1.4)$ & $-0.7(1.3)$ \\
Gestational age (w) & $38.9(2.8)$ & $38.9(2.6)$ \\
Neonatal jaundice & $62 \%$ & $21 \%$ \\
Neonatal hypoglycaemia & $43 \%$ & $10 \%$ \\
Micropenis (\% of boys) & $38 \%$ & $17 \%$ \\
Age at start of GH treatment $(\mathrm{y})$ & $4.0(3.5)$ & $6.4(3.4)$ \\
Height SDS at start of GH & $-3.0(1.3)$ & $-3.2(0.9)$ \\
GH peak during Arginine test $(\mu \mathrm{g} / \mathrm{L})$ & $1.7(2.0)$ & $3.1(2.0)$ \\
GH peak during Clonidine test $(\mu \mathrm{g} / \mathrm{L})$ & $1.5(1.3)$ & $3.7(2.0)$ \\
IGF-I SDS & $-4.4(3.0)$ & $-3.3(2.4)$ \\
Thyroid hormone replacement & $100 \%$ & $14 \%$ \\
Hydrocortison treatment & $79 \%$ & 0 \\
Induction of puberty & $85 \%$ & 0 \\
Hypoprolactinemia & $15 \%$ & 0 \\
Diabetes insipidus & $5 \%$ & 0 \\
Affected first-degree relatives & $5 \%$ & $7 \%$ \\
\hline
\end{tabular}

Data are expressed as mean (SD) or \%

$S D S$ standard deviation score

${ }^{a}$ No cases of central hypothyroidism, only primary hypothyroidism or borderline low FT4 values during GH therapy pituitary hormone deficiencies, were present in 62, 43 and $38 \%$ (of boys), respectively. 79 patients underwent MRI, $82 \%$ of them had an abnormal pituitary on MRI (Figure S1). Clinical characteristics of the (p)IGHD patients screened for defects in the HESX1 promoter are also shown in Table 1.

We identified nine genetic variants in the CPHD cohort; six in the regulatory regions of $P R O P 1$ and three in the regulatory regions of $P O U 1 F 1$ (Table 2). We did not find any variants in the HESX1 promoter in either the (p)IGHD or CPHD patients. Four of the PROP 1 promoter SNPs have been previously reported by Godi et al. [7]. The genotype frequencies did not differ significantly from the frequencies found in healthy controls from the 1000 Genome Project (Table 2).

A polymorphism in $P R O P 1$, consisting of a $3 \mathrm{bp}$ (TAG) deletion in the promoter (ins/delTAG, rs148607624), which was previously shown to be more frequent among CPHD patients than among controls [7], was associated with a slightly more severe phenotype (i.e. shorter height, lower peak GH during GH test, and lower serum IGF-I SD scores) in the current cohort (Table 3). The other SNPs were not related to phenotype.

One of the POUIF1 variants had not been reported in the 1000 Genomes database by January 2017. We found this new heterozygous variant, $-1295 \mathrm{C}>\mathrm{T}$ in a girl born Small for Gestational Age (SGA) (2500 $\mathrm{g}$ and $45 \mathrm{~cm}$ after $41 \mathrm{w}$ of gestation). At 6 months of age, her length was - 4.3 SDS. After endocrine function tests, she was diagnosed with $\mathrm{GH}$ deficiency and later with central hypothyroidism. She also required hydrocortisone treatment and sex steroid treatment

Table 2 New and known variants in the regulatory regions of PROP1, POU1F1 and HESX1 in the current study, compared to British control data from the 1000 genomes database

\begin{tabular}{lll}
\hline Gene & rs number & $\begin{array}{l}\text { Frequency }(\%) \text { in } \\
\text { current study/British } \\
\text { controls* }(\mathrm{p})\end{array}$ \\
\hline POU1F1 promoter & $\begin{array}{l}\text { New variant } \\
(-1295 \mathrm{C}>\mathrm{T})\end{array}$ & $1.1 /-(\mathrm{NS})$ \\
POU1F1 promoter & rs10511134 $(\mathrm{T}>\mathrm{A})$ & $43.8 / 50.5(\mathrm{NS})$ \\
POU1F1 promoter & rs300982 $(\mathrm{C}>\mathrm{T})$ & $10.9 / 3.8(\mathrm{NS})$ \\
POU1F1 DRR & No variants found & - \\
PROP1 CEA & rs12654239 (G $>\mathrm{T})$ & $61.4 / 53.3(\mathrm{NS})$ \\
PROP1 CEB & rs4431364 $(\mathrm{C}>\mathrm{G})$ & $28.9 / 31.9(\mathrm{NS})$ \\
PROP1 CEB & rs4498267 $(\mathrm{C}>\mathrm{T})$ & $12.5 / 13.2(\mathrm{NS})$ \\
PROP1 CEB & rs148607624 (ins/ & $1.7 / 0.5(\mathrm{NS})$ \\
& delTAG) & \\
PROP1 CEB & rs141213827 (delG) & $1.1 / 0(\mathrm{NS})$ \\
PROP1 CEB & rs113776172 (C $>$ A) & $1.1 / 0(\mathrm{NS})$ \\
HESX1 promoter & No variants found & - \\
\hline
\end{tabular}

$N S$ not significant 
Table 3 Severity of GHD phenotype according to $P R O P 1$ SNP rs148607624 (ins/delTAG)

\begin{tabular}{|c|c|c|c|c|c|c|}
\hline & $\mathrm{N}$ & Mean & SD & Min & $\operatorname{Max}$ & $\mathrm{p}$ \\
\hline \multicolumn{7}{|c|}{ Height at start of GH treatment } \\
\hline TAG/TAG & 84 & -3.1 & 1.3 & -6.0 & 0.0 & \multirow[t]{2}{*}{0.22} \\
\hline$-/ \mathrm{TAG}$ & $2^{\mathrm{a}}$ & -4.2 & 0.4 & -4.5 & -4.0 & \\
\hline \multicolumn{7}{|c|}{ Mean of peak GH values during clonidine and arginine tests $(\mu \mathrm{g} / \mathrm{L})$} \\
\hline TAG/TAG & 53 & 1.8 & 2.1 & 0.0 & 9.4 & \multirow[t]{2}{*}{0.49} \\
\hline$-/ \mathrm{TAG}$ & 3 & 0.9 & 0.9 & 0.0 & 1.7 & \\
\hline \multicolumn{7}{|c|}{ IGF-I SDS at start of GH treatment } \\
\hline TAG/TAG & 57 & -3.8 & 2.5 & -9.4 & 1.4 & \multirow[t]{2}{*}{0.010} \\
\hline$-/ \mathrm{TAG}$ & 3 & -7.8 & 2.1 & -9.0 & -5.3 & \\
\hline
\end{tabular}

${ }^{a}$ Numbers do not add up to 88, because height SDS at start GH was not available for two patients. In these two patients, GH was started based on deficiencies of all other pituitary axes, low IGF-I SDS and two severely deficient $\mathrm{GH}$ tests due to lack of pubertal development. Her MRI revealed no visible abnormalities.

To predict the possible impact of this new POU1F1 promoter variant, we performed in silico analysis using online software. The binding sites for several transcription factors disappear when the C located 1295 bp upstream of the transcription start site is replaced by a $\mathrm{T}$. In addition, the new variant creates new binding sites for other transcription factors, shown in Supplementary table S1, which means that transcription of POU1F1 might be affected by this variant.

\section{Discussion}

We studied the regulatory regions of the pituitary transcription factors PROPI, POUIFI and HESXI in a cohort of 88 CPHD patients, in order to find an explanation for their phenotype. Since patients with HESXI mutations can initially present with IGHD only, we also screened 92 patients with severe or partial IGHD (64 M/28 F).

In the CPHD patients, we identified eight known polymorphisms (six in the regulatory regions of $P R O P I$ and two in the regulatory regions of $P O U 1 F 1$ ) and one new $P O U 1 F 1$ variant. No variants in the $H E S X 1$ promoter were identified in the 88 CPHD and 92 (p)IGHD patients.

Since CPHD can be caused by both heterozygous and homozygous POU1F1 mutations, the new heterozygous POU1F1 promoter variant $-1295 \mathrm{C}>\mathrm{T}$ could be the cause of CPHD in this patient. We performed in silico analysis to predict its possible impact, which showed that the -1295 $\mathrm{C}>\mathrm{T}$ variant might create new binding sites for several transcription factors in the $P O U 1 F 1$ promoter region. In theory, this could increase or decrease the activity of the promoter, and therefore alter the expression of POUIF1. However, even though this new variant might explain the phenotype of this individual patient, the general conclusion of this study is that variants in regulatory regions of $P R O P 1, P O U 1 F 1$ and HESXI are rare in patients with sporadic CPHD in the Netherlands.

These results are very important for clinicians and researchers in the field of congenital hypopituitarism. Most clinicians routinely send DNA of their familial and sporadic CPHD patients to genetic laboratories for genetic screening of PROP1, POU1F1 and HESX1. However, the chance of finding a mutation in these genes in a CPHD patient depends strongly on the country of origin and is very low for Western European countries, especially for the Netherlands. Our previous study already showed that the vast majority of Dutch sporadic CPHD cases could not be explained by defects in the coding regions of PROPI, POUIF1 and HESX1 [24]. The results of the current study show that defects in their regulatory regions do not explain the phenotype either.

Based on the current study and our previous studies investigating pituitary transcription factors, we therefore recommend that genetic screening of $P R O P 1, P O U 1 F 1$ and HESX1 should no longer be part of routine work-up for sporadic CPHD patients in the Netherlands.

The fact that we studied a Dutch cohort, suggests that our results only justify recommendations for Dutch patients. However, similar recommendations might also apply to other Western European countries, because of our shared genetic background. The genetic composition of European countries is in part determined by human migration in the Paleolithic and Neolithic periods, but also by more recent migration in the fifteenth and seventeenth century. The genetic background seems to be comparable for most Western European countries, except for the Iberian Peninsula. This has been confirmed by recent research concerning PROPI mutation frequencies in different countries $[32,33]$. PROP1 mutation rates are highest in Russian, Eastern European, Portuguese and Brazilian cohorts. In Western and Southern European Countries, PROPI frequencies among sporadic CPHD patients are generally low (United Kingdom 0\%, Spain 5.6\%, Portugal 6.9\%, 
Italy $2.9 \%$, Fig. 1b). De Rienzo et al. [33] state that after excluding Russian, Eastern European, Portuguese and Brazilian cohorts, the global frequency of PROP1 mutation decreases from 11.2 to $5.1 \%$ (a decrease from 6.7 to $1.9 \%$ in sporadic patients and $48.5-35.8 \%$ in familial cases). The mutation prevalence found in the current Dutch cohort is among the lowest in Europe.

In the case of sporadic CPHD, mutations are only likely to be identified in patients from countries with a high prevalence of mutations and patients who present with a phenotype that strongly favours the analysis of a particular gene, such as LHX3 (hypopituitarism, sensorineural hearing loss and skeletal abnormalities) or HESXI (hypopituitarism and SOD) [33]. Parents of sporadic CPHD patients without these specific phenotypes should be informed about these low mutation rates in order to prevent false expectations.

In contrast to sporadic cases, familial subjects from all countries should undergo genetic analysis if possible. In these familial cases, the likelihood of detecting a mutation within any of the transcription factor genes is much higher [10-16, 19, 20, 33].

In conclusion, mutations in the regulatory regions of pituitary transcription factors $P R O P 1, P O U 1 F 1$ and HESX1 are rare in Western Europe, especially in the Netherlands. Based on this and previous studies of our group, and based on mutation frequencies from other countries, we conclude that these mutations do not significantly contribute to the prevalence of IGHD or CPHD. We therefore recommend against routine genetic screening of $P R O P 1$, POU1F1 and HESXI among sporadic CPHD patients in Western Europe, especially in the Netherlands. Further research should focus on the identification of new candidate genes, using a whole genome/exome approach.

Acknowledgements We would like to thank Ward et al. for kindly providing the sequences for both the PCR and sequence primers, as well as the conditions for the PCR, of CEA and CEB of PROPI. In addition we would like to thank Godi et al. for the sequence of the forward primer they used to amplify PROPI CEB. We would like to thank Dr Ángel Campos Barros (Madrid, Spain) for help in POU1F1 and HESX1 primer design. We thank Esther de Beus, research assistant, for collection of blood samples and clinical data; Bonnie Bakri, Matthieu van der Vlist and Janneke Baan, medical students, for their help during collection of clinical data.

\section{Compliance with ethical standards}

Conflict of interest The authors declare that they have no conflict of interest.

Ethical approval All procedures performed in this study were in accordance with the ethical standards of the institutional and/or national research committee and with the 1964 Helsinki declaration and its later amendments or comparable ethical standards. We obtained approval from the medical ethics committees of all participating hospitals.
Informed consent Informed consent was obtained from all individuals participating in this study and their parents if they were less than 18 years old.

Open Access This article is distributed under the terms of the Creative Commons Attribution 4.0 International License (http://creativecommons.org/licenses/by/4.0/), which permits unrestricted use, distribution, and reproduction in any medium, provided you give appropriate credit to the original author(s) and the source, provide a link to the Creative Commons license, and indicate if changes were made.

\section{References}

1. Pfäffle R, Klammt J (2011) Pituitary transcription factors in the aetiology of combined pituitary hormone deficiency. Rev Best Pract Res Clin Endocrinol Metab 25(1):43-60

2. de Moraes DC, Vaisman M, Conceição FL, Ortiga-Carvalho TM (2012) Pituitary development: a complex, temporal regulated process dependent on specific transcriptional factors. Rev J Endocrinol 215(2):239-245

3. Cushman LJ, Watkins-Chow DE, Brinkmeier ML, Raetzman LT, Radak AL, Lloyd RV, Camper SA (2001) Persistent Prop1 expression delays gonadotrope differentiation and enhances pituitary tumor susceptibility. Hum Mol Genet 10(11):1141-1153

4. Savage JJ, Yaden BC, Kiratipranon P et al (2003) Transcriptional control during mammalian anterior pituitary development. Gene 319:1-19

5. Zhu X, Gleiberman AS, Rosenfeld MG (2007) Molecular physiology of pituitary development: signaling and transcriptional networks. Physiol Rev 87:933-963

6. Kelberman D, Rizzoti K, Lovell-Badge R, Robinson I, Dattani M (2009) Genetic regulation of pituitary gland development in human and mouse. Endocrinol Rev 30(7):790-829

7. Godi M, Mellone S, Tiradani L, Marabese R, Bardelli C, Salerno M, Prodam F, Bellone S, Petri A, Momigliano-Richiardi P et al (2012) Functional SNPs within the intron 1 of the PROP1 gene contribute to combined growth hormone deficiency (CPHD). J Clin Endocrinol Metab 97(9):E1791-E1797

8. Coya R, Vela A, Pérez de Nanclares G, Rica I, Castaño L, Busturia MA, Martul P, GEDPIT Group (2007) Panhypopituitarism: genetic versus acquired etiological factors. J Pediatr Endocrinol Metab 20(1):27-36

9. Kim SS, Kim Y, Shin YL, Kim GH, Kim TU, Yoo HW (2003) Clinical characteristics and molecular analysis of PIT1. PROP1, LHX3, and HESX1 in combined pituitary hormone deficiency patients with abnormal pituitary MR imaging. Horm Res 60:277-283

10. McLennan K, Jeske Y, Cotterill A et al (2003) Combined pituitary hormone deficiency in Australian children: clinical and genetic correlates. Clin Endocrinol (Oxf) 58:785-794

11. Rainbow LA, Rees SA, Shaikh MG et al (2005) Mutation analysis of POUF-1, PROP-1 and HESX-1 show low frequency of mutations in children with sporadic forms of combined pituitary hormone deficiency and septo-optic dysplasia. Clin Endocrinol (Oxf) 62:163-168

12. Osorio MG, Marui S, Jorge AA et al (2002) Pituitary magnetic resonance imaging and function in patients with growth hormone deficiency with and without mutations in GHRH-R, GH-1, or PROP-1 genes. J Clin Endocrinol Metab 87:5076-5084

13. Lebl J, Vosáhlo J, Pfaeffle RW et al (2005) Auxological and endocrine phenotype in a population- based cohort of patients with PROP1 gene defects. Eur J Endocrinol 153:389-396 
14. Lemos MC, Gomes L, Bastos M et al (2006) PROPl gene analysis in Portuguese patients with combined pituitary hormone deficiency. Clin Endocrinol (Oxf) 65:479-485

15. Fofanova OV, Takamura N, Kinoshita E et al (1998) A mutational hot spot in the Prop-1 gene in Russian children with combined pituitary hormone deficiency. Pituitary 1:45-49

16. Navardauskaite R, Dusatkova P, Obermannova B et al (2014) High prevalence of $P R O P 1$ defects in Lithuania: phenotypic findings in an ethnically homogenous cohort of patients with multiple pituitary hormone deficiency. J Clin Endocrinol Metab 99:299-306

17. Dateki S, Fukami M, Uematsu A, Kaji M, Iso M, Ono M, Mizota M, Yokoya S, Motomura K, Kinoshita E, Moriuchi H, Ogata T (2010) Mutation and gene copy number analyses of six pituitary transcription factor genes in 71 patients with combined pituitary hormone deficiency: identification of a single patient with LHX4 deletion. J Clin Endocrinol Metab 95(8):4043-4047

18. Diaczok D, Romero C, Zunich J, Marshall I, Radovick S (2008) A novel dominant negative mutation of OTX2 associated with combined pituitary hormone deficiency. J Clin Endocrinol Metab 93(11):4351-4359

19. Fritez N, Sobrier ML, Iraqi H, Vié-Luton MP, Netchine I, El Annas A, Pantel J, Collot N, Rose S, Piterboth W, Legendre M, Chraibi A, Amselem S, Kadiri A, Hilal L (2015) Molecular screening of a large cohort of Moroccan patients with congenital hypopituitarism. Clin Endocrinol (Oxf) 82(6):876-884

20. Baş F, Uyguner ZO, Darendeliler F, Aycan Z, Çetinkaya E, Berberoğlu M, Şiklar Z, Öcal G, Darcan Ş, Gökşen D, Topaloğlu AK, Yüksel B, Özbek MN, Ercan O, Evliyaoğlu O, Çetinkaya S, Şen Y, Atabek E, Toksoy G, Aydin BK, Bundak R (2015) Molecular analysis of PROP1, POU1F1, LHX3, and HESX1 in Turkish patients with combined pituitary hormone deficiency: a multicenter study. Endocrine 49(2):479-491

21. Reynaud R, Gueydan M, Saveanu A, Vallette-Kasic S, Enjalbert A, Brue T, Barlier A (2006) Genetic screening of combined pituitary hormone deficiency: experience in 195 patients. J Clin Endocrinol Metab 91:3329-3336

22. Del Blanco DG, de Graaff LC, Visser TJ, Hokken-Koelega AC (2013) Single nucleotide variants in two Hedgehog genes, SHH and HHIP, as genetic cause of combined pituitary hormone deficiency. Clin Endocrinol (Oxf) 78(3):415-423

23. Gorbenko Del Blanco D, Romero CJ, Diaczok D, de Graaff LC, Radovick S, Hokken-Koelega AC (2012) A novel OTX2 mutation in a patient with combined pituitary hormone deficiency, pituitary malformation and an underdeveloped left optic nerve. Eur J Endocrinol 167(3):441-452

24. de Graaff LC, Argente J, Veenma DC, Drent ML, Uitterlinden AG, Hokken-Koelega AC (2010) PROP1, HESX1, POU1F1, LHX3 and LHX4 mutation and deletion screening and GH1 P89L and
IVS3 $+1 /+2$ mutation screening in a Dutch nationwide cohort of patients with combined pituitary hormone deficiency. Horm Res Paediatr 73(5):363-371

25. de Graaff LC, Argente J, van Meurs JB, Uitterlinden AG, HokkenKoelega AC (2010) Genetic polymorphisms in the locus control region and promoter of GH1 are related to serum IGF-I levels and height in patients with isolated growth hormone deficiency and healthy controls. Horm Res Paediatr 73(1):25-34

26. de Graaff LC, Argente J, Veenma DC, Herrebout MA, Friesema EC, Uitterlinden AG, Drent ML, Campos-Barros A, HokkenKoelega AC (2009) Genetic screening of a Dutch population with isolated GH deficiency (IGHD). Clin Endocrinol (Oxf) 70(5):742-750

27. Gorbenko Del Blanco D, de Graaff LC, Posthouwer D, Visser TJ, Hokken-Koelega AC (2011) Isolated GH deficiency: mutation screening and copy number analysis of HMGA2 and CDK6 genes. Eur J Endocrinol 165(4):537-544

28. Delhase M, Castrillo JL, de la Hoya M, Rajas F, Hooghe-Peters EL (1996) AP-1 and Oct-1 transcription factors down-regulate the expression of the human PIT1/GHF1 gene. J Biol Chem 271(50):32349-32358

29. Eroshkin F, Kazanskaya O, Martynova N, Zaraisky A (2002) Characterization of cis-regulatory elements of the homeobox gene Xanf-1. Gene 285(1-2):279-286

30. Ward RD, Davis SW, Cho M, Esposito C, Lyons RH, Cheng JF, Rubin EM, Rhodes SJ, Raetzman LT, Smith TP et al (2007) Comparative genomics reveals functional transcriptional control sequences in the PROP1 gene. Mamm Genome 18:521-537

31. Messeguer X, Farré D, Nuñez O, Martínez J, Albà MM (2002) PROMO: detection of known transcription regulatory elements using species-tailored searches. Bioinformatics 18(2):333-334

32. Dusatkova P, Pfäffle R, Brown MR, Akulevich N, Arnhold IJ, Kalina MA, Kot K, Krzisnik C, Lemos MC, Malikova J, Navardauskaite R, Obermannova B, Pribilincova Z, Sallai A, Stipancic G, Verkauskiene R, Cinek O, Blum WF, Parks JS, Austerlitz F, Lebl J (2016) Genesis of two most prevalent PROP1 gene variants causing combined pituitary hormone deficiency in 21 populations. Eur J Hum Genet 24(3):415-420

33. De Rienzo F, Mellone S, Bellone S, Babu D, Fusco I, Prodam F, Petri A, Muniswamy R, De Luca F, Salerno M, MomiglianoRichardi P, Bona G, Giordano M, Italian Study Group on Genetics of CPHD (2015) Frequency of genetic defects in combined pituitary hormone deficiency: a systematic review and analysis of a multicentre Italian cohort. Clin Endocrinol (Oxf) 83(6):849-860 